\title{
Upstream Social Marketing Strategy
}

\section{Dr. Ann-Marie Kennedy (Corresponding author)}

Senior Lecturer - Department of Management, Marketing and Entrepreneurship

School of Business,

University of Canterbury

Address: Private Bag 4800, Christchurch 8140

New Zealand

Email: ann-marie.kennedy@ canterbury.ac.nz

Phone: +64 33694602 ext 94602

\section{Joya Kemper}

$\mathrm{PhD}$ - Department of Management, Marketing and Entrepreneurship

School of Business,

University of Canterbury

Address: Private Bag 4800, Christchurch 8140

New Zealand

Email: joya.kemper@pg.canterbury.ac.nz

\section{Professor Andrew Parsons}

Head of Subject Group - Marketing and Sales

Faculty of Business and Law,

University of Portsmouth

Address: Portland Street, Richmond Building

PO1 3DE, Portsmouth

United Kingdom 


\title{
Upstream Social Marketing Strategy
}

\begin{abstract}
In the case of complex social problems such as obesity and environmental degradation, structural change is needed to provide people with the ability to change (Andreasen, 2006). Strategic social marketing has identified upstream social marketing as a method to influence structural change through policy makers (French \& Gordon, 2015), however literature in the area tends to be descriptive and there are no clear guidelines to its implementation (Dibb, 2014). This article seeks to provide those guidelines. First it looks at the characteristics of policy makers targeted, then targeting methods, with a special focus on the use of media advocacy. Lastly a process of government decision making is presented to explain message timing and content.
\end{abstract}

Keywords: Upstream social marketing, strategic social marketing, social marketing, media advocacy. 


\section{Introduction}

Influencing decision makers 'upstream' from a wicked problem is one avenue to address these complex problems such as obesity, environmental degradation, fast fashion and drug use (Gortmaker et al., 2011; Rittel \& Webber, 1973; Kennedy, 2016). Upstream social marketing may target individuals at the organisation, industry or government level. Those in key policy decision positions for mitigating wicked problems. Rittel and Webber (1973) surmised that wicked problems are messy and difficult to define, with multiple, interlinked, perpetuating factors (for further information see Commonwealth of Australia, 2012). There are no straightforward causes and solutions to wicked problems. This is due to their complexity, uncertainty, and divergence of interpretation, and often rely "on political judgments rather than scientific certitudes" (Head 2008, p. 102) which can amount in many ethical issues (Szablewska and Kubacki 2017). Upstream social marketing provides a method to influence the political judgements of upstream decision makers.

A key criticism of social marketing is that it tends to focus on individual and community level change without addressing upstream contextual and environmental factors (Wallack, Dorfman, Jernigan \& Themba, 1993). Not only is downstream social marketing in danger of becoming expert driven instead of citizen driven, but individual level interventions assume a personal responsibility and consumer sovereignty that may not exist for all problems (Cherrier \& Gurrieri, 2014; French \& Gordon, 2015). Consequently, structural change is aimed at policy makers and implementers but is often difficult to achieve (Andreasen, 2006) through strategic social marketing. Strategic social marketing can be defined as "The systematic, critical and reflexive application of social marketing principals to enhance social policy selection, objective setting, planning and operational delivery" (French \& Gordon, 2015, p. 45). Strategic social marketing goes beyond the tactical level of social marketing in its co-ordination with community and upstream actors. 
Upstream social marketing is a method for social marketers to influence policy and solution adoption as it focuses on the macro/structural environment moving beyond the individual or community level of down- and mid-stream social marketing. It specifically tries to create behaviour and attitude change in "voting behaviours, activity in policy debates and cabinet and committee meetings, judgements, corporate policies, adjudications and applications of legal principles and precedents" (Gordon, 2013, p. 1530). The upstream social marketing metaphor comes from Wallack et al. (1993) which describes how individuals are swept down a stream with the social marketer needing to examine up the stream to see why. Upstream social marketing charges social marketers to look at what environmental conditions are problematic and how they can be changed to create a supportive environment for behaviour and attitude change (Cherrier \& Gurrieri, 2014).

Current research on upstream social marketing has looked at contexts including limiting alcohol and cigarette consumption (Hassan, Walsh, Shiu, Hastings \& Harris 2007; Hastings, 2007; Cherrier \& Gurrieri, 2014; Gordon, 2013), by limiting advertising (Hastings, Anderson, Cook \& Gordon, 2005), limiting product use in public spaces (Moore, Perham \& Shephard, 2006), and through licencing (MacNaughton \& Gillan, 2011) and pricing (Meier, Purshouse \& Brennan, 2010). Additionally, research has examined waste reduction, increases in recycling and healthy eating (Thomas \& Sharp, 2013), water fluoridation, and policies on substance misuse in schools (Hastings, 2007; Stead et al., 2007). Furthermore, previous research has also examined the interaction between upstream, midstream and downstream intervention of more holistic programs (Cherrier \& Gurrieri, 2014).

Unfortunately, while there are a lot of descriptions and analyses of upstream social marketing, often identifying causes of behaviour (Wallack et al., 1993), not much attention has been given to the operationalisation of upstream social marketing (Smith, 1998; Wymer, 2011; Hoek \& Jones, 2011; Dibb, 2014; Gordon, 2013). This article seeks to provide a 
framework to guide the upstream social marketing process. Specifically, it provides guidance to the implementer of upstream social marketing on 1) Choosing who to target upstream;2) How to communicate with upstream actors; 3) Communications that are most useful to social marketers at the stage of upstream actors' decision making; and 4) When to provide communications for maximum effectiveness.

\section{Upstream Social Marketing}

Governments are moving towards a more consultative, community generated process of problem solving, especially with wicked problems (Dibb, 2014). Indeed, wicked problems need debate and discussion, and active co-creation (Dibb \& Carrigan, 2013). A more holistic approach to social marketing, where macro contexts of behaviours and attitudes are couched, is advocated (Collins, Tapp \& Pressley, 2010). An holistic approach to social marketing, especially for wicked problems is needed as one clear individual level solution is impossible (Rittel \& Webber, 1973). Consequently, both individual behaviours and structural and environmental factors contributing to these situations need be addressed (Cherrier \& Gurrieri, 2014; Demers et al., 2002).

Upstream social marketing is suitable for problems that are a high cost to society and aims to "alter the institutions that form the social system within which the individual operates" (Goldberg, 1995, p. 365). This type of social marketing tries to shape the environmental context of behaviour through influencing policy and regulation. Targeting the upstream is important as it acknowledges and works toward changing structures, institutions, systems and other aspects of society and the community that collaborate to enforce or perpetuate harmful individual behaviours (Raphael, 2003). Upstream social marketing used in this way could be part of an overall macro-social marketing strategy. Specifically, macrosocial marketing considers the whole system that perpetuates an issue, and upstream social 
marketing is one of the many tools that can be used to influence that system. Policy plays a crucial role in reducing harmful behaviours such as smoking (Kennedy, 2017), especially so when considering the 'myth' of individual responsibility and consumer sovereignty for highly addictive behaviours (Hoek \& Jones, 2011). Social marketing techniques can influence policy makers through "the adaptation and application of marketing and other approaches, to change the behaviour of decision makers and opinion formers which alters the structural environment and has a resultant positive influence on social issues" (Gordon, 2013, p. 1525).

Altering the structural environment through upstream social marketing can be instigated by numerous types of individuals, groups and organisations, effect various upstream actors, and effect differing elements of the structural environment. Upstream social marketing can be undertaken by many groups or cluster of actors. Upstream social marketers could be, but are not limited to, community groups, non-government organisations (NGO), industry associations, and individual businesses. Those who aim to influence the structural environment can target their effects at individuals or groups involved in policy making (e.g. upstream actors/decision makers) at the macro (government, council) or meso (firm, school) level (Hastings et al., 2000). For example, this may include law makers, regulators, or policy makers (i.e. politicians, regulatory authority or body, or boards of directors), and may involve those with greater impact on policy making than those utilising upstream social marketing itself, such as trade groups, industry lobbyists and industry associations.

The aim of contacting individuals or groups involved in policy making is to influence the structural environment by adjusting or creating new policies, such as laws, regulations or funding opportunities and includes lobbying. Utilising the work by Michie, van Stralen, and West (2011), Kemper and Ballantine (2017) suggest that macro-social marketers through upstream social marketing, can influence various policy or intervention tools. These are fiscal (e.g. tax), communication/marketing (e.g. social marketing), service provision (e.g. 
workshops, helplines), legislation (e.g. import bans), regulation (e.g. advertising restrictions), guidelines, and environmental/social planning (e.g. zoning). While macro-social marketing is a macro-level approach and believes in structural change through combined efforts at the micro, meso and macro level (Kennedy, 2016), upstream social marketing is but one tool for systemic change to occur. As such, while upstream social marketing is part of a macro-social marketing strategy, what is presented here focuses more in depth on upstream social marketing rather than at all three macro, meso and micro levels at once. The focus of this paper is on the tools to influence policy makers (eg upstream social marketing).

Background research is needed to understand the best policy tool(s) relevant to each social problem. To influence the change or adoption of new interventions and tools, groups aiming to utilise upstream social marketing have several strategies they can adopt. Unfortunately, there are no clear guidelines for upstream social marketers to use to effectively target decision makers. As such, the purpose of this article is to expand on how upstream social marketing is best implemented, discussing how and when communication with upstream actors is most appropriate.

While upstream social marketing can take on lobbyist's strategies to influence policy, it also includes promotion, advocacy, framing, PR and media relations, (market) research and information (Gordon, 2012; Wymer, 2011). Specifically, upstream social marketing interventions need to be based on consumer research and methods such as promotion, education and advocacy are used to disseminate that information. In addition, stakeholder engagement and mobilisation are important, and PR and media advocacy can be used to gain support for, and awareness of social issues, related research, and issue causes and solutions (Hastings, 2007; Gordon, 2013).

A lack of development in the field of upstream social marketing is due to a cautious approach to not over step the boundaries of the social marketing discipline and to remain 
focused on individual level behaviour change (Gordon, 2013). Tapp and Spotswood (2013) also credit this stagnation of the field to a lack of recognition of the strategic potential for social marketing. However, this is shifting with the publication of strategic social marketing books (French \& Gordon, 2015) and a recognition that a combination of up-, mid- and downstream social marketing is needed for effective social change (Andreasen, 2002; Dibb \& Carrigan, 2013; French \& Blair-Stevens, 2010; French \& Gordon, 2015; Tapp \& Spotswood, 2013).

Policy makers' decisions are most typically made from a range of options presented to them instead of a complex and holistic evaluation of the environment (Goldberg, 1995). Policy can be influenced by knowledgeable and invested actors, whether they be academic researchers, non-government organisations (NGOs), community groups, organisations, or charities. Such actors hoping to influence the structural environment and thus upstream actors need to be knowledgeable about specific target audiences, their needs, value sought, beliefs and level of knowledge, and be able to provide evidence of intervention success (French \& Gordon, 2015).

\section{Guidelines for Upstream Social Marketing Strategy}

Following is a set of guidelines, based on the literature, for actors wishing to influence upstream decision makers. As such, those actors will now be referred to as upstream social marketers. This does not mean that these actors have the job title "upstream social marketer" but could be members of community groups, organisations, lobby groups, businesses or individuals. Specifically, for these actors to be considered upstream social marketers, they would target those in decision making positions upstream from them. This could include decision makers at the organisation, industry, regulatory or political level of a country. The following guidelines direct upstream social marketers in planning and implementing an 
upstream social marketing strategy to influence the decisions of their identified targets. To aid the reader, the complete set of guidelines is presented here in Table 1, before being discussed in detail in the following sections. First the key areas to assess when conducting background research is explained before segmenting and targeting of decision makers. Then a detailed model of decision making is presented, allowing for insight regarding social marketer message communication content and timing. Consequently, this article seeks to cover guidelines on whom, how and when social marketers can undertake upstream social marketing. Throughout the discussion, examples are provided to clarify concepts for the reader. Often the context of the fashion industry is used, however this article is not meant as a case study or remedy for that context. It is purely meant as illustrative (for full case studies of fast fashion please see Kennedy et al, 2017; Kennedy, 2016; Ertekin and Atick, 2015).

\section{Guidelines for Upstream Social Marketing Strategy}

\section{Conduct Background Research}

a. Assess prior conditions affecting the adoption of a sought social change, such as:

i. Previous societal practices regarding social change.

ii. Their response to social change in general.

iii. The needs and problems of the society.

iv. The level of innovation within the society.

v. Societal norms that may dictate which social changes are acceptable.

\section{Segmenting and Targeting Decision Makers}

a. Assess their view on social marketing in general (if you are advocating a social marketing intervention).

b. Assess if they are in pre-contemplation or contemplation stage on issue.

c. Assess decision makers' rationale, ideology, emotional and moral reactions to social threats and change, public and political motivations and institutional restrictions.

d. Decide who to target based on above assessment.

\section{Assess Stage of Decision Process}

a. Using parliamentary debates, policy proposals, political speeches and agendas, and the media, assess which stage of the decision process the 


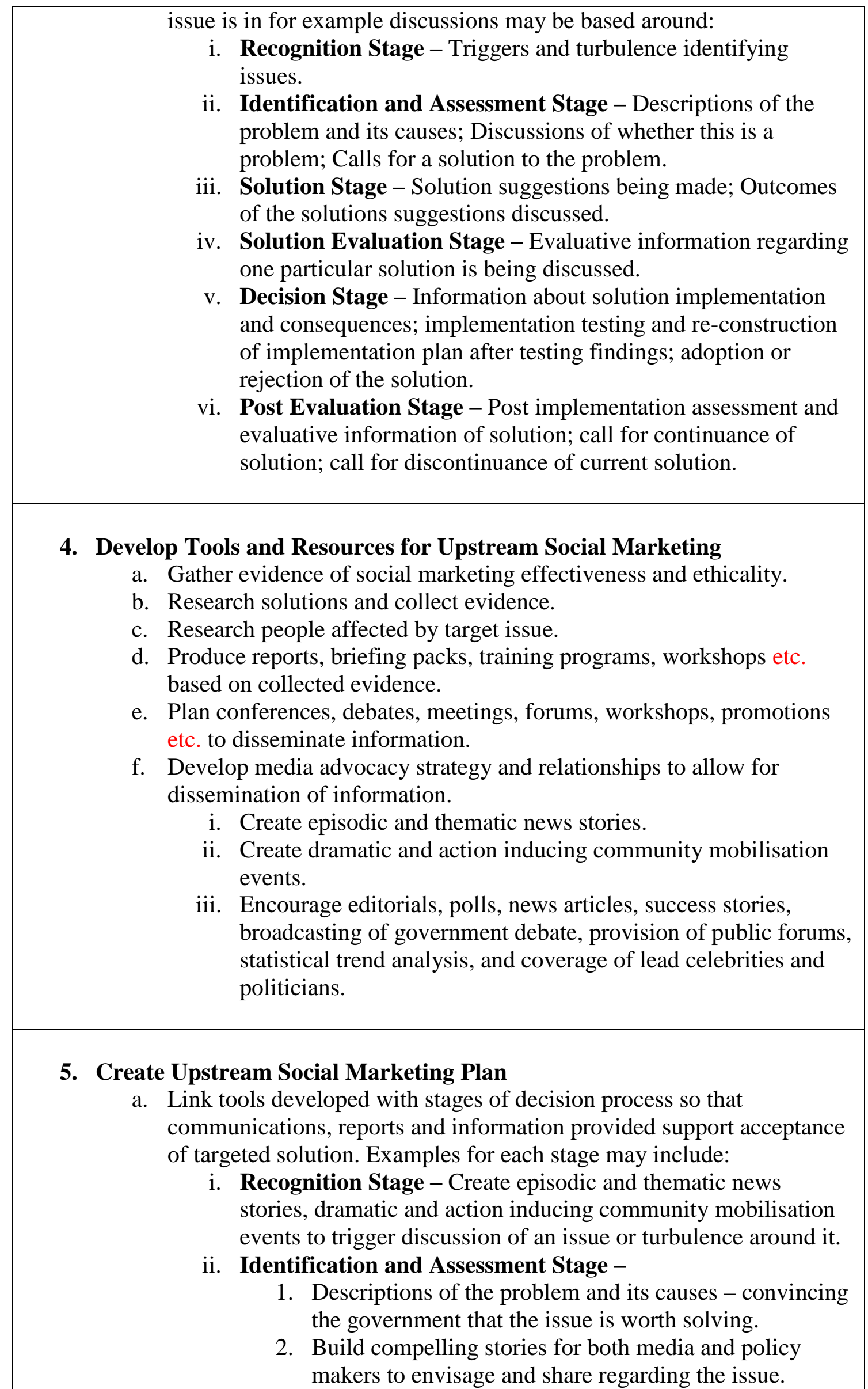


iii. Solution Stage -

3. Call for a solution to the problem using public forums and community mobilisation events.

4. Assess whether the decision will become an optional, collective, authority or contingent decision for the decision-making unit.

1. Assess the characteristics of the key decision-making unit with regards the solution: socio-economic channels, communication behaviours and personality variables.

2. Suggest solutions via promotion, media advocacy and research reports. Make sure solutions are assessed for whether they are continuous, dynamically continuous or discontinuous innovations.

3. Provide evidence of measures of performance and outcomes sought from suggested solutions in public forums, reports, white papers, promotion and media advocacy.

4. Seek one-on-one communication of the above with targeted politicians, opinion leaders and solution champions.

\section{iv. Solution Evaluation Stage -}

1. Provide evaluative information to help policy makers defend the solution through marketing communications, media advocacy, policy development forums, white papers, debates, interpersonal communications and reports etc.

2. Evaluative information needs to address:

a. The relative advantages over other solutions,

b. Compatibility with the needs and values of the society,

c. Trialability and outcome of trials,

d. Complexity decreased and,

e. Observability of trials or observed outcomes from other places.

3. If the solution is a continuous innovation, this will decrease the need for trial of the solution. However, the relative advantage and observability of it will be important to emphasise.

4. A dynamically continuous solution will require more emphasis on the relative advantages, trialability and observability aspects of the solution.

5. A discontinuous solution will require heavy emphasis on all aspects of the solution.

v. Decision Stage - Provide information and research on solution testing, implementation and consequences through reports, polls, interviews, statistics, success stories etc.

vi. Post Evaluation Stage - Provide post implementation assessment and evaluative information of solution via reports, polls, trends, interviews, statistics etc.

b. Constant scanning of the environment is needed to recognise changes 
in stages and loop backs as well as appropriate resources, activities, stories etc. to roll out at the appropriate time.

Table 1: Guidelines for Upstream Social Marketing Strategy

\section{Conduct Background Research}

In considering social change, firstly society's background must be understood. Such understanding comes from reviewing the social institutions, both formal (laws) and informal (culture, social norms), which effect the current status of wicked problems as well as the adoption and preference for solutions and initiatives. All prior conditions affecting the adoption of a sought social change should be considered, including previous societal practices regarding social change, and their response to social change in general. The more innovative a society or social system considers themselves, the more open they will be to social changes (Rogers, 2003).

As such, social systems consist of norms and values supported by societal consensus. Norms and values provide frameworks for appropriate or acceptable behaviour (Dixon 1984). Specifically, communication norms may dictate the speed and efficiency of innovation information (i.e. how fast new information is distributed), and social norms and values may dictate which social changes are acceptable (i.e. policy interventions). Further, if there are norms and taboos surrounding social issues and changes, the change may be blocked as people refuse to talk about them (Alexander \& Schmidt, 1996; Cherns, 1976; Kocowski, 1976; Mannheim, 1940). Marketing influences, perpetuates and communicates these social norms, values and beliefs (Dixon 1984). Consequently, social norms and values must be considered when researching and investigating appropriate interventions. Specifically, norms and values will influence how solutions should be framed. Additionally, the needs and problems of the society will affect social change acceptance, and thus also need to be researched. 
For example, in fast fashion, consumers have become used to and now often demand cheap and fashionable clothes. Retailers respond to consumer demands for low cost fashionable clothing. As a result, this feeds the fast fashion industry with constant additions to product lines, resulting in cheap and poor quality products, due to cost and time restraints on suppliers (Ertekin \& Atik, 2015). In turn, this produces a disposable lifestyle for consumers, resulting in obsolescence and excessive waste (Ertekin \& Atik, 2015). However, these externalities are often not realised by the consumer (Bruce \& Daly, 2006). Such norms and perpetuating factors make changes to the fast fashion industry difficult and rallied against (Kennedy, et al, 2017).

\section{Segmenting and Targeting Decision Makers}

Once the state of play has been assessed, decision makers need to be considered, segmented and those most appropriate targeted. Decision makers may present one of four types of views on social issues (French, 2013). Consequently, each view has different opinions on the need for and/or affinity for specific interventions. Views include those who are opposed to or sceptical of social issues and/or intervention(s) versus those who are worried about, or support social issues and/or intervention(s). The common thread between these views is that the use of evidence of the chosen intervention(s) and its impact and effectiveness can be used to prove or nurture support of a given solution.

According to Andreasen (2006), decision makers need to be further broken up into pre contemplators and contemplators. Pre contemplators don't see the target behaviour (social issue) as a problem or are unaware that it exists; media can be used to bring the social issue to the fore. Contemplators are aware of the social issue but need to be prompted to move from contemplation to preparation and action stages. There are many different approaches for this to be implemented. A core understanding of each target decision makers' rationale, ideology, 
emotional and moral reactions to social threats and change, and motivations, as well as the institutional structures that restrict them, are needed to bolster the effectiveness of upstream social marketing tactics (French \& Gordon, 2015; Lindblom \& Woodhouse, 1993; Gordon, 2013).

Beyond decision makers' views of social issues and interventions, their general characteristics also need to be assessed. Characteristics of the decision-making unit include their socio-economic channels, communication behaviours and personality variables which all may affect the speed and efficiency of information flow as well as other aspects of decision making (Alexander \& Schmidt, 1996; Kojder, 1996; Rogers, 2003; French, 2013). Such characteristics may not be variables that can be changed by the upstream social marketer; however, awareness of them may give more viability to planning processes and measurement (Goldberg, 1995

Understanding what matters to the decision maker such as getting re-elected or meeting efficacy and effectiveness outcomes/measures and public's perception is key (Gordon, 2013; French, 2014). Creating a narrative for actors about the value of certain new or adjusted policies for themselves (i.e. getting re-elected, popularity) and for society is equally important (i.e. decreased health costs). Information provided by upstream social marketers help policy makers to better represent their citizens, have clear objectives and outcomes of interventions, identify poorly performing interventions and guide investment in future interventions (French \& Gordon, 2015). Media is a very important vehicle for bringing such information into the public sphere, as well as social mobilisation (Boorstin, 1992).

\section{Assess Stage of Decision Process}

Lastly, once the target decision maker has been identified, their position or stage in the decision-making process regarding the issue needs to be addressed. The Upstream Decision 
Making Process (UDMP - Figure 1) shows the progression of an upstream actor's decisions. Certain techniques can be used at different stages and with varying emphasis in the decisionmaking process. Upstream social marketing techniques use during the process serves to influence decision maker's views of the problem and solutions, and thus is a means to influence the adoption of a solution (Alexander \& McDonald, 1996; Lazarsfeld, Berelson \& Gaudet, 1948; Lin \& Burt, 1975; Mannheim, 1940; Rogers, 2003; Andreasen, 2006; French \& Gordon, 2015; Lindblom, 1980). Certain techniques also help with spreading awareness and general information about the social issue and solutions, and can represent evaluative information (Yankelovich, 1991; Andreasen, 2006, French \& Gordon, 2015).

\section{[Insert Figure 1 Here]}

Conceptually, the UDMP assumes that upstream social marketers aim to have their intervention/solution diffuse through the decision-making unit to provide a higher chance of adoption and retention of their solution in the long run. The diffusion process considers a solution's communication through a social system (Rogers, 2003), and views a social system as a group of people who are interrelated because of a common problem. This is particularly appropriate for upstream social marketers who may be dealing with a working committee assigned to remedy the problem they are concerned about. The structure of the social system will influence the innovation's diffusion, and diffusion may in turn, alter the society's structure (Rogers, 2003).

Stages of upstream decision making formation follow a general format where issues are first defined, solutions debated, and then solutions developed through further debate and compromise (Braybrooke \& Lindblom, 1970; Ferrell \& Krugman, 1978; Hastak, et al., 2001).

Each of the stages of the UDMP originate from the work of Podgorecki (1990) and Rogers (2003), among others. The Recognition stage (Podgórecki, 1990) is where a trigger occurs which unbalances or creates turbulence within the society and brings a problem/need 
or possibility to the fore (Alexander \& Schmidt, 1996; Lazarsfeld \& Reitz, 1975). At the Identification and Assessment stage, the problem perceived in the Recognition stage is explored. Description of the problem and its context is sought, and the worth of solving the problem is assessed by matching it with the values of society (Podgórecki, 1990; Alexander \& McDonald, 1996; Yankelovich, 1991; Etzioni, 1976; Kocowski, 1976). The solution stage searches for ways to solve the problem (Alexander \& McDonald, 1996; Alexander \& Schmidt, 1996; Kocowski, 1976; Podgórecki, 1990; Yankelovich, 1991). During the solution stage, desired outcomes must be articulated first, before solutions can be identified, and it is here where knowledge is sought of how each intervention or solution may work (Rogers, 2003; Goldberg 1995; Hastings, 2007).

Moderating factors for the solution stage include the characteristics of the decisionmaking unit and the solution itself. The characteristics of the decision-making unit have been discussed in the segmenting section of this paper so we shall now turn to the characteristics of the suggested solutions. Solutions could be a continuous, a dynamically continuous or a discontinuous innovation. A continuous innovation is a solution which is an extension of an existing solution. Therefore, it will be less complex and more compatible with society's beliefs and practices. For example, to combat cheaply imported clothing in the fast fashion dilemma, social marketing efforts may already exist to promote locally made products, this campaign could be extended to include messages of "fair price" and "fair wage". A dynamically continuous innovation is one that may be more disruptive than the continuous innovation, but it is still based on existing solutions used. These solutions require a little more understanding and linking to the current beliefs and practices of the society. An example of this (but certainly not a complete solution) could be voluntary supply chain audits to ensure human rights standards are met for clothing and textile industry workers, which are promoted and supported by the Government, governing body or an NGO. A discontinuous innovation is 
a solution that is different from any that are in place at the time and following it involves changes in behaviour (Robertson, 1967), for example in the case of fast fashion, this could be stipulations in free trade arrangements about fair trade pricing and mandatory minimum working conditions for imported clothing.

Evaluations of each solution and its consequences take place at the solution evaluation stage (French \& Gordon, 2015, Alexander \& McDonald, 1996; Lazarsfeld \& Reitz, 1975; Mannheim, 1940; Rogers, 2003; Zetterberg, 1962). The moderators that affect this stage are the perceived characteristics of the solution itself which are relative advantage, compatibility, trialability, complexity and observability. The relative advantage of the solution is apparent when it is compared with current solutions (Andreasen, 2006). Compatibility is the amount a solution is seen to be attuned with the social system's past experiences, values and needs. The third attribute of solutions that will affect the rate of diffusion is complexity. Complexity is how difficult the solution is to understand as well as how difficult it is to use; the more complex, the slower the rate of diffusion. Trialability is how easy it is to be able to trial a solution for a shorter period of time or with a smaller group of people, and is the fourth aspect that will affect adoption rates. Lastly, observability is how visible the benefits of the solution are to others (Rogers, 2003).

The decision stage is the first time that behavioural actions take place as opposed to purely cognitive. An implementation plan for each solution is formed and tested and its consequences are considered and adjusted for (Lazarsfeld \& Reitz, 1975; Podgórecki, 1990; Podgórecki \& Łoś, 1979; Yankelovich, 1991). This is similar to the evaluation of the solution, however the evaluations that are made here are not theorised but actually tested. The decision stage is where the solution is accepted or rejected on the macro level. Thus, it is here where there is another feedback loop - if the solution is rejected then the process reverts back to the solution stage and a search continues for more solutions. For example, if a 
discontinuous solution (e.g. mandatory fair trade pricing) for fast fashion is rejected proponents may revert to a simpler intervention such as a continuous or dynamically continuous solution (such as voluntary supply chain audits).

Finally, the post evaluation stage is where the use of the solution is assessed and its effects are truly understood. Again, the solution may be changed or rejected (French \& Gordon, 2015; Lazarsfeld \& Reitz, 1975; Podgórecki, 1990; Popper, 1945; Rogers, 2003). If the solution is rejected then the process starts at the solution stage again with an alternative solution. For instance, if there was a lack of uptake of voluntary supply chain audits a more dynamically continuous solution might be considered if there is enough political will, such as mandatory labels about where, how and who made specific clothing items.

For upstream social marketer's viewpoints to be brought to the attention of the upstream actors, the exact time and content of their message needs to be chosen for maximum effect, whether that be communicated through the media, education, advertising or personal communications etc (Ferrell \& Krugman, 1978; Lindblom, 1980; Goldberg, 1995). Refining the UDMP, Table 2 provides specific themes which will be present in decision makers' rhetoric, helping the upstream social marketer to identify where they are in their decisionmaking process. These themes can be garnered from speeches, websites, news articles, policy documents and reports released (among other communications) by decision making units, as well as their actions, such as creation of a committee to deal with a particular issue. For an event to be considered as representing a particular stage, it must feature one (or all) of the criteria outlined under that stage of the table.

\begin{tabular}{||c|c|c|c|c||}
\hline $\begin{array}{c}\text { Identification \& } \\
\text { Assessment Stage }\end{array}$ & Solution Stage & $\begin{array}{c}\text { Solution } \\
\text { Evaluation Stage }\end{array}$ & Decision Stage & $\begin{array}{c}\text { Post Evaluation } \\
\text { Stage }\end{array}$ \\
\hline $\begin{array}{c}\text { Description of the } \\
\text { problem and its }\end{array}$ & $\begin{array}{c}\text { Solution } \\
\text { suggestions }\end{array}$ & $\begin{array}{c}\text { Evaluative } \\
\text { information } \\
\text { regarding the }\end{array}$ & $\begin{array}{c}\text { Information about } \\
\text { solution } \\
\text { implementation and }\end{array}$ & $\begin{array}{c}\text { Post implementation } \\
\text { assessment and }\end{array}$ \\
\hline
\end{tabular}




\begin{tabular}{|c|c|c|c|c|}
\hline causes & & \multirow{3}{*}{$\begin{array}{l}\text { solution such as: } \\
\text { Characteristics of } \\
\text { the solution; } \\
\text { Relative } \\
\text { advantages; Ability } \\
\text { to trial; } \\
\text { Compatibility; } \\
\text { Complexity; } \\
\text { Ability to observe }\end{array}$} & consequences & $\begin{array}{c}\text { evaluative } \\
\text { information of } \\
\text { solution }\end{array}$ \\
\hline $\begin{array}{c}\text { Discussion of } \\
\text { whether this is a } \\
\text { problem }\end{array}$ & \multirow{2}{*}{$\begin{array}{l}\text { Outcomes of the } \\
\text { solution }\end{array}$} & & $\begin{array}{l}\text { Implementation } \\
\text { testing and Re- } \\
\text { construction of } \\
\text { implementation plan } \\
\text { after testing findings }\end{array}$ & $\begin{array}{c}\text { Call for continuance } \\
\text { of solution }\end{array}$ \\
\hline $\begin{array}{l}\text { Call for a solution } \\
\text { to a problem }\end{array}$ & & & $\begin{array}{l}\text { Adopt or Reject } \\
\text { solution }\end{array}$ & $\begin{array}{c}\text { Call for } \\
\text { discontinuance of } \\
\text { current solution }\end{array}$ \\
\hline
\end{tabular}

Table 2: Criteria to Apply the Government Decision Process to Events

\section{Develop Tools and Resources for Upstream Social Marketing}

There are many tactics to influence decision makers. As outlined by French (2013), these include seminars, conferences, debates and workshops highlighting evidence of new or adjusted policies effectiveness. In addition, producing research, reports and briefing packs, on top of training on intervention options in general and the effectiveness of particular solutions specifically. Upstream social marketers can also use promotion, advocacy, lobbying, politicisation, public opinion polls, PR and media advocacy (Gordon, 2012; Wymer, 2011). Additionally, they can further facilitate other interested parties, such as charities and special interest groups, to interact with policy makers.

Media advocacy has been identified as part of a broader strategy of social change (Wallack, 2002), and has been identified as the most important method for social change (Hornik, 1995). For example, previous research has found that failure to meet social marketing strategic objectives was from not using media coverage and media advocacy to change perspectives and behaviour for a given problem (Gordon, 2012; Stead, Gordon, Angus \& McDermott, 2007). Media advocacy targets policy makers and others who can be mobilised to influence them (Wallack, 2002). Specifically, upstream social marketers utilise the influence and power of the media to exert pressure on decision makers (i.e. individuals or 
committees) for effective, and usually specific, policy change (Dorfman \& Krasnow, 2014). Media advocacy frames an issue in a broader societal context, identifies contributing factors, mobilises and creates pressure for policy change. This could be in the form of editorials, news and PR from experts, community and organisation of citizens (Bentz, Dorfman, Denniston, Novelli, 2005).

News media play a big role in how we frame events and issues, and what issues we think about. Media can be used to highlight environmental, social and economic issues and bring them into the public sphere (Andreasen, 2006). News media have been found to frame social issues episodically, by only focusing on an individual's story without contextual details; this type of framing is not typically associated with holding society responsible for policy change but may help highlight or call attention to specific issues (McKeever, 2013). Conversely, thematic framing, where stories are told from a societal perspective (Iyengar, 1991), has been argued to be more effective in helping people understand society's role in solving issues and thus supporting collective instead of individual action (McKeever, 2013). Thus, social marketers may need to make thematic stories as powerful and emotional as episodic stories. Specifically, upstream social marketers must think about what they can provide to the media and reporters that will help them create an interesting and powerful story that supports the overall policy or intervention goal. To do so, they may use the story elements of authentic voices (spokespeople), media bites (concise statements/stories), localisation of stories (local comparisons and statistics), and visuals (McKeever, 2013).

Stories provided to the media need to be dramatic and action inducing such as with community mobilisation events like rallies and demonstrations when possible (Andreasen, 2006; Boorstin, 1992; Bentz et al., 2005). While mobilisation has been discussed in previous issues such as obesity (Huang et al., 2015), not all communities can be mobilised as well as others. Additionally, while media advocacy can help bring about a consistent message across 
the media, mobilising this in the form of supportive public opinion that will help implement effective regulatory policies is much harder (Elliott-Green, Hyseni, Lloyd-Williams, Bromley \& Capewell, 2016). However, social media has opened other avenues to interact with groups and individuals who may influence the media advocacy and policy-making processes, which includes researching social movements, understanding viewpoints, and mobilising support for a solution through campaigning, boycotting or protest (McKeever, 2013).

Media can be used, not only to bring an issue into the public attention, but also to outline and promote solutions, and monitor and support the solutions implemented. This can be done through talk shows, conferences, news and success stories, editorials, polls, broadcasting government debate, provision of public forums for discussion and debate, provision of guidelines, and trends and coverage of celebrities and political leaders and their dealings with the issue and/or its solutions. As such, social marketers can target both content creators and transmitters in the way of news as well as entertainment media (Andreasen, 2006). It is essential that actors have an access strategy, outlining how they will gain access to journalists, bloggers, celebrities and social media stars, among others (McKeever, 2013).

\section{Create Upstream Social Marketing Plan}

Once a pool of resources has been created, upstream social marketers must decide when to deploy each resource for maximum effect. By considering the stages in the UDMP, and assessing where their target decision maker is in these stages, communications can be tailored to best persuade the target decision maker. Alternatively, depending on the stage, communications can be provided to support the targeted decision maker by giving them the evidence they need to convince others and have the target solution trialled, adopted, or retained. In the following sections, examples of how an upstream social marketer can be most 
effective at each stage of the UDMP is presented. It includes information on content and most effective type of communication.

\section{The Recognition Stage}

At the recognition stage, social marketers can use mass media as a tool to create turbulence and awareness of a problem, using advertising or media releases (Alexander \& McDonald, 1996; Hay, 1996; Andreasen, 2006). However, the specific trigger of this problem may only be able to be identified retrospectively. There are ethical issues that present themselves with this aspect, please see Szablewska and Kubacki (2017) for a discussion.

This stage is about the perception of the problem within current circumstances and the awareness of the problem itself. Consequently, framing the social issue is especially important at this stage, helping to aid the understanding of the issue (i.e. its causes) and an intervention or solution that is palatable to the public. Recognition of the problem and its possible solutions can come from such channels as the news (Podgórecki, 1990), or social events such as a down turn in the economy (Scott, 1998). Mass media campaigns may be used at the recognition stage to create turbulence and awareness of the problem possibly through advertising or media releases (Alexander \& McDonald, 1996; Hay, 1996; Andreasen, 2006). In summary, the recognition stage is where the perception and awareness of the problem occurs.

An example of this is the 2013 Bangladesh factory collapse which killed 1,127 people and highlighted the costs and consequences of fast fashion which demands cheap labour and results in horrific working conditions (Taplin, 2014). This spawned a public outcry over clothing and textile worker's conditions and set in motion further transparency in clothing retailer's supply chains and helped initiate the Bangladesh Safety Accord (Oxfam, 2013). 


\section{The Identification and Assessment Stage}

At the identification and assessment stage, the problem is described and the extent of the problem is estimated. This is done through the collection and sorting of facts regarding the issue, its current situation and its causes (Podgórecki, 1990). Marketing communications and media can be used to convince upstream actors that the problem is worth solving (Alexander \& McDonald, 1996; Hay ,1996; Andreasen, 2006; French, 2014). At this stage the voices of the public and other concerned parties must be heard and mobilised by upstream social marketers (i.e. community groups, NGOs). One example is the creation of the organisation Fashion Revolution who run social media campaigns throughout the year mobilising consumers to pressure fashion retailers for supply chain transparency. This stage is partly carried out through identifying the values of society. If the issue is seen as a problem, then this may reflect the values of society, such as safe working conditions. Sometimes it may simply be anomalies that are noticed, or favouritism that is perceived, and this may be due to the messy nature of current public policy, or advances in things like technology overtaking policy. In the case of a national crisis for example, an issue is something that becomes very real for many people, and the assessment of the problem by various stakeholders shows the issue(s) as requiring public policy intervention, such as seen in the Bangladesh factory collapse. Upstream social marketers should build compelling stories for both media and policy makers to envisage the need for change and share possible solutions for the issue (French, 2014).

The upstream social marketer's strategy will change depending on whether solutions reflect optional, collective, authority or contingent decisions (Rogers, 2003). An optional decision is one in which each group or individual can choose to adopt the solution themselves (e.g. encouraging the purchase of slow fashion). In this case, such as with encouraging a 
rejection of fast fashion, downstream social marketing would be the most appropriate route forward. The upstream social marketer may then be seeking funds for media campaigns or influencing retailers to stock slow fashion brands. A collective decision however is in which the choice to adopt a solution is decided by the whole social group involved (e.g. adoption of industry guidelines by voting). Such a decision would then be seeking again downstream social marketing interventions to influence individual voting behaviour and so would not be appropriate for upstream decision making strategy. An authority decision happens when only one group in society decides whether to adopt or reject a solution that individuals then must all follow (e.g. a law such as for provision of a living wage to clothing and textile workers). While all other groups have little bearing on the decision, they must all follow the solution once it has been adopted by the decision-making group. Such decisions are particularly suited to upstream social marketing. Lastly, a contingent decision is a two-step process whereby a solution has to be adopted before each individual can then decide whether they will individually adopt that solution (e.g. subsidies for providing living wages to clothing and textile workers). It is important to differentiate between a contingent and authority decision, as the contingent decision would require the social marketer to also instigate a two-step process, first of upstream social marketing to influence the initial decision, then of downstream social marketing to influence uptake of the solution.

\section{The Solution Stage}

At the solution stage, solutions are generated and information is sought to help decrease uncertainty over the solution and its effects (Podgórecki, 1990; French \& Gordon, 2015; Stromsdorfer, 1985). Marketing communications and media can be used by stakeholders at this stage of the process (Alexander \& McDonald, 1996; Hay, 1996; Lazarsfeld, et al., 1948; 
Narasimhan \& Sen, 1983; Rogers, 2003) to bring about awareness and knowledge of possible solutions and their impact (Alexander \& McDonald, 1996; Hay, 1996; Rogers, 2003).

Recent literature in social marketing has been addressing how to identify solutions to a problem. Uncovering perpetuating institutional norms has been suggested as one form of solution identification (Kennedy, 2016), for example as discussed by Taplin (2014), who identified the institutional framework that facilitates and encourages local firms to participate in the fast fashion system. Such norms can be uncovered and solutions suggested through a systems analysis using MAS theory (Kennedy, Kapitan, Bajaj, Bakonyi and Sands, 2017). MAS theory refers to the interaction between marketing systems, action fields and social mechanisms and how they evolve (see Layton, 2014 for full details). Involvement of stakeholders in a co-discovery and co-design process has also been proposed by Domegan et al. (2013), which could be undertaken through using a stakeholder Interactive Management process to uncover the vastly different barriers and solutions to systemic issues (Domegan et al. 2016).

At the solution stage, interpersonal communications are considered the most effective form of communication, generally when seeking evaluative information about the solution from a person's peers, especially in the case of opinion leaders (Rogers, 2003). However, opinion leaders must first gain their information from source(s). One such source is marketing communications and the mass media, as opinion leaders are seen to be more media savvy than other consumers (Rogers, 2003; Andreasen, 2006). Lobbying specific politicians and special interest groups are also involved at this stage (for instance clothing industry bodies, such as the Sustainable Apparel Coalition, Outdoor Industry Association, the Fair Labour Association and BlueSign). While interpersonal communications are more effective, it is more difficult for stakeholders to use in public policy situations because of the size and dispersion of typical societies and the stakeholder groups within. Therefore, another option is 
(mass) marketing communication (Lin \& Burt, 1975; Robertson, 1967) and media with emphasis on consumer research (Hastings, 2007).

\section{The Solution Evaluation Stage}

In the solution evaluation stage, an attitude or opinion about the solution is formed and evaluative information is sought. Evaluative information can be dispersed by upstream social marketers through marketing communications, media, policy development forums, white papers, debates, interpersonal communications and reports (Alexander \& McDonald, 1996; Yankelovich, 1991; French, 2013; French \& Gordon, 2015).

Solutions are evaluated, as discussed previously, on their relative advantage, compatibility, trialability, complexity and observability. Marketing communications and the mass media can successfully be used to present evaluative information regarding the implemented solution (Andreasen, 2006; Alexander \& McDonald, 1996; Hay, 1996; Narasimhan \& Sen, 1983). In this stage, each of the characteristics of the solution can be presented through marketing communications and media in order to help the evaluative process. All of this may be done through the use of marketing communications and the media, especially advertising, incentives, and other related promotions and support services such as debates and interviews (Narasimhan \& Sen, 1983; French, 2013; Andreasen, 2006).

The relative advantage of the solution to other suggested solutions can now be compared. This comparison can be conducted through using a cost-benefit analysis of the solution; these characteristics may be influenced by upstream social marketers to increase the likelihood of acceptance/rejection of the solution. The evaluation process may also loop back to the solution stage if the solution does not meet the evaluative criteria set by the decision making group. Awareness of new solutions would occur at this stage (Rogers, 2003). 
Providing the costs and benefits of solutions to policy makers, as well as evidence of the solution's success, helps the upstream actor to defend the program they are putting forward. Benefits need to be specific to the situation and as outlined by French and Gordon (2015) could include: “1) improved relevance for target groups, 2) better policy coherence, 3) enhanced learning, 4) mobilise partners' assets, 5) improved ROI and VFM tracking," while costs could include: "1) increased investment in scoping research and co-ordination, 2) pain of change and disruption, 3) loss of control, 4) transition costs, 5) increased development time" (p. 374).

Upstream social marketers can highlight how the solution is compatible with the needs and values of the society If the solution is compatible with prior knowledge in the social system, stakeholders will be less uncertain about the solution and its impact. However, for the solution to match the needs of the social system, policy makers need to know its benefits - that is, what needs it fulfils, for them to be able to judge its compatibility.

The complexity of the solution can be decreased through presenting it in a clear and concise manner and also through its explanation in media and other communications. Complex solutions are often either hard for upstream decision makers to understand or to explain, and to convince others of. Therefore, anything an upstream social marketer can do to decrease the level of complexity of an offered solution can improve the likelihood of its trial. Infographics are a new way to present complex information graphically, as are posters, which may help with explanation. For example, presenting the wages earned by fashion factory workers and their working conditions in a simple but eye-catching way may inform consumers about previously unknown working conditions in developing countries.

If the solution itself cannot be observed, its benefits can be presented, and if trial is not possible then observation may also be a useful tactic (Rogers, 2003). However, trialling is the best strategy, as it reduces the amount of uncertainty surrounding it and thus increases the 
likelihood of adoption. Upstream social marketer's reporting of consumer research and trials of the solution or experiments and other research aid this aspect (Goldberg, 1995). For instance, any downstream social marketing efforts to highlight the unfair and unsafe working conditions of labourers in clothing factories must be evaluated by consumers (i.e. a fall in sales, change in attitudes) as well as business responses (i.e. uptake of supply chain audits, creating minimum standard working conditions in their supply chain network). Being able to observe the benefits of a solution will increase the rate of diffusion (Rogers, 2003). For instance, trialling an intervention in one community and using that as an example with polls and trend statistics will help observation of benefits of the solution. Such issues as heart disease, where solutions may take many years for their benefits to be realised, for example, increasing exercise or improving diet, is a long-term solution.

\section{The Decision (and Implementation) Stage}

In the decision and implementation stage, chosen solutions are tested and thus rejected or refined. Upstream social marketers can provide polls, interviews, statistics, and success stories to support this aspect (Andreasen, 2006). Once one particular solution is decided upon, information about how to attain the solution, how to use it, and its potential consequences, is specifically collated. For example, once the solution, such as dynamically continuous in the case of fast fashion (i.e. voluntary supply chain audit), has been decided upon, the specific details of the voluntary supply chain audit must be refined (i.e. what are the thresholds of minimum wage and working conditions) and key players must be brought on board (i.e. Zara and H\&M). This is also the stage where the solution is implemented (Popper, 1945; Rogers, 2003) and mid or downstream social marketers may also step in.

\section{The Post Evaluation Stage}


After solution implementation, a solution is almost never guaranteed to be protected from future evaluation, nor should it be. It is up to the upstream social marketer to continue to assess the solution effectiveness and provide evaluative criteria to the upstream target person(s). As with the problem recognition stage, marketing communications and media can be used to raise awareness of problems with the solution and gauge discontent with the solution as well (Andreasen, 2006; Goldberg, 1995; Rogers, 2003). For example, engaging in media advocacy to raise awareness of the issue and solution amongst the population by harnessing the power of TV talk shows, news media, and political debates.

\section{Discussion}

This article has sought to provide guidelines for the implementation of upstream social marketing (Table 1). We first discussed the different types of upstream actors, what interventions can be used to change the structural environment, and how these upstream actors can be targeted. Next, we discussed the timing and content of messages as outlined through the stages of the UDMP (Figure 1).

According to these guidelines first upstream social marketers must conduct background research on society and the conditions affecting the adoption of a sought social change. Next, decision makers need to be assessed and segmented, based on their views of the social issue in question and intervention advocated and their motivations. Assessment of which stage in the decision process the issue is in comes next and guidelines on how this can be identified are provided. Then the upstream social marketer needs to start developing tools, methods and resources to communicate and influence upstream actors. This is through research, communications and media advocacy. Lastly, they need to form an upstream social marketing plan by linking their tools, methods and resources to the stages of the decision process presented in this article. Examples for each stage are provided, along with message 
content and other considerations. Constant scanning of the political environment is needed to be able to follow changes from one stage to the next, or loops through stages. The use and timing of upstream social marketers' tactics and strategies can be influenced by the stage decision makers (i.e. government, governing body, board of directors) are in.

Often, public policy issues are debated, defined and redefined in the media. The media is frequently used as another vehicle for the flow of society's opinions on upstream issues (Ferrell \& Krugman, 1978; Lindblom, 1980; Pappalardo \& Ringold, 2000; Andreasen, 2006). However, other methods for upstream social marketing can also be applied at each stage (i.e. seminars, debates, workshops, reports, media advocacy, lobbying) (French \& Gordon, 2015). Communication can come from change agents, opinion leaders and general marketing activities, and diffusion can occur through intended or unintended activities (Rogers, 2003).

However, diffusion of a solution is never guaranteed. Consideration of the characteristics of decision makers may not uncover their key influencers or power struggles. For instance, in the case of fast fashion, the background narratives of stakeholders have revealed a power imbalance where the status quo (e.g. fast fashion) is favoured because of a drive for economic development by both governance units, retailers and consumers (Kennedy et al, 2017). As such, any solution suggested that goes against a drive for economic development will be difficult to implement, no matter how persuasive the arguments for these solutions may be. In these cases, a bottom up approach and community mobilisation may be more effective. Some success has been seen in this way from organisation such as the Fashion Revolution, whose "Who made my clothes" campaign has seen greater transparency in over 3000 retailers, driven by consumers posting \#whomademyclothes on retailer social media pages (Fashion Revolution, 2017) 
Such community mobilisation also begs the question as to who upstream social marketing is best aimed at. Should it be government, industry bodies (such as the Advertising Authority), individual organisations, or something else? Each of these groups provides their own special cluster of conundrums and barriers to effectively implementing upstream social marketing. While a judgement of this is beyond the scope of this paper, consideration of the background characteristics of each group within the segmentation process will create the right level of clarity needed for each individual upstream social marketer. Consideration of the level of influence of each group and the type of decision (authority, contingent etc.) will aid in both segmenting and choosing between target markets. For instance, if an industry body such as the UN Global Compact requires self-regulation and self-reporting of compliance with regulation, with little to no recompense for breaking regulations, then targeting such a group could well be ineffectual (Laczniak and Kennedy, 2011).

Alternatively, we do not advocate here the lack of feedback loops for proper evaluation of the consequences of implementation of any upstream solution. By being part of a system, upstream social marketing solutions may have unintended consequences and knock on effects that negatively impact a group. Such consequences may be seen in the implementation of trade regulations for safe and fair working conditions which may decrease the number of jobs available in developing countries leading to higher unemployment. Without feedback loops and constant evaluation of solutions and their consequences, negative impacts could be left unchecked to the detriment of society.

While one of the contributions of this article is the UDMP, there are alternative models available in the literature. Ferrell and Krugman (1978) have offered a few suggestions to increase input into public policy decisions, such as restructuring government to enable more input and direct consideration of consumer welfare. They place each of these approaches squarely under the responsibility of the government. Deliberative democracy is 
offered by Ozanne, et al. (2009) where stakeholder input can be facilitated through organised meetings (Cornwall \& Gaventa, 2000). Others have advocated the use of surveys and marketing research (Finn \& Louviere, 1992; Hastak, Mazis \& Morris, 2001; Robin, 1987). However, the problem with such approaches is that they rely on the government to facilitate more input and then to use that input (Ozanne, et al., 2009). No specific ways in which groups can enable themselves to be heard are presented in previous works, and they are effectively 'top down' approaches only.

In particularly complex issues, the UDMP may need to be used multiple times at multiple levels simultaneously to be effective. For instance, an upstream social marketer advocating for a living wage for textile and clothing producers may need to target their home country Government regarding trading laws, local retailers regarding payment to manufacturers, foreign manufacturers employing the workers, and foreign industry bodies they belong to all at once in the aim of making a change. If this is the case, then the guidelines outlined here need to be undertaken for each group. Background information on each group would first be collected, each group would be segmented and a target selected from each, and then tools and a strategy for implementation created for each target. The complexities for such an endeavour are multifaceted and we would suggest the more complex and layered the approach needs to be, the more difficult its success. However, such an iterative approach would be necessary. Future research on the implementation of these guidelines in general, but especially for more complex issues, is needed.

Reflecting on the possibilities for upstream social marketing, future research should make use of these guidelines in the manner of case studies, interviews and historical accounts to provide further support for strategies and processes employed here. Specific contexts for case studies for investigation could be a more extended example of fast fashion, as well as other wicked issues such as obesity and sustainability in the food chain. Additionally, future 
research should examine how the targeting approach and decision making processes are similar or differ at the meso (community, firm) versus macro (Government) level. Lastly, not all efforts by upstream social marketers, namely lobbyist for industry associations which harm health and society (e.g. tobacco industry), are beneficial for society. As such, a fruitful area of research might be on examining the processes and strategies which may help disrupt lobbyists actions through upstream social marketing, and their ethical implications.

\section{Conclusion}

By providing guidelines for upstream social marketers this article has contributed to the social marketing literature. Previously there have been no clear guidelines for step-bystep implementation of upstream social marketing and this article seeks to remedy this knowledge gap. Specifically, this paper provides information for social marketers to aid who to target (upstream from them); when and how to communicate with these actors (through mass media, marketing communications, or one-on-one interpersonal communications); and what to include in those communications for maximum effectiveness. The timing and content of the guidelines are based on a conceptual framework which is another contribution of this article. The UDMP shows a decision making process with feedback loops and moderating factors which help to uncover which content will be especially persuasive and when to provide such content to upstream social marketers. We hope this article might allow social marketers to become 'activists' and change makers in upstream issues (Wymer, 2011). 


\section{References}

Alexander, J., \& MacDonald, M. (1996). Elite Leadership of Collective Attitudes Toward Competitiveness: The Help Wanted Campaigns. In A. Podgórecki, J. Alexander and R. Shields (Eds.), Social Engineering (pp.317-340). Canada: Carleton University Press.

Alexander, J., \& Schmidt, J. (1996). Social Engineering: Genealogy of a Concept. In A. Podgórecki, J. Alexander and R. Shields (Eds.). Social Engineering (pp.1-20). Canada: Carleton University Press.

Andreasen, A. R. (2002). Marketing social marketing in the social change marketplace. Journal of Public Policy \& Marketing, 21(1), 3-13.

Andreasen, A. R. (2006). Social marketing in the 21st century. Sage Publications.

Bennett, R., Kerrigan, F., O'Reilly, D., Szmigin, I., Bengry-Howell, A., Griffin, C., ...Mistral, W. (2011). Social marketing, individual responsibility and the "culture of intoxication”. European Journal of Marketing, 45(5), 759-779.

Bentz, J. W., Dorfman, L., Denniston, R., \& Novelli, W. (2005). Opportunities for social change through upstream partnerships. Social Marketing Quarterly, 11(3-4), 17-25.

Boorstin, D. J. (1992). The Image-a guide to pseudo-events in America. New York: Vintage. Harper's.

Braybrooke, D. \& Lindblom, C.E. (1980). A Strategy of Decision: Policy Evaluation as a Social Process. New York: The Free Press.

Bruce, M., and Daly, L. (2006), "Buyer behaviour for fast fashion," Journal of Fashion Marketing and Management, 10(3), 329-344. 
Cherrier, H., \& Gurrieri, L. (2014). Framing social marketing as a system of interaction: A neo-institutional approach to alcohol abstinence. Journal of Marketing Management, $30(7-8), 607-633$.

Collins, K., Tapp, A., \& Pressley, A. (2010). Social marketing and social influences: Using social ecology as a theoretical framework. Journal of Marketing Management, 26(1314), 1181-1200.

Commonwealth of Australia. (2012). Tackling wicked problems: A public policy perspective. Retrieved from http://www.apsc.gov.au/publications-and-media/archive/publicationsarchive/tackling-wicked-problems

Cornwall, A. \& Gaventa, J. (2000). From Users and Choosers to Makers and Shapers: Repositioning Participation in Social Policy. IDS Bulletin, 31 (4), 50-62.

Demers, A., Kairouz, S., Adlaf, E., Gliksman, L., Newton-Taylor, B., \& Marchand, A. (2002). Multilevel analysis of situational drinking among Canadian undergraduates. Social science \& medicine, 55(3), 415-424.

Dibb, S., \& Carrigan, M. (2013). Social marketing transformed: Kotler, Polonsky and Hastings reflect on social marketing in a period of social change. European Journal of Marketing, 47(9), 1376-1398.

Dibb, Marylyn Carrigan, S., \& Gordon, R. (2013). Unlocking the potential of upstream social marketing. European Journal of Marketing, 47(9), 1525-1547.

Dibb, S. (2014). Up, up and away: social marketing breaks free. Journal of Marketing Management, 30(11-12), 1159-1185.

Dixon, D. F. (1984). Macromarketing: A Social Systems Perspective. Journal of Macromarketing, 4 (2), 4-17. 
Domegan, C., Collins, K., Stead, M., McHugh, P. \& Hughes, (2013) "Value co-creation in social marketing: functional or fanciful?", Journal of Social Marketing, 3 (3), 239256.

Domegan, C., McHugh, P., Devaney, M., Duane, S., Hogan, M., Broome, B.J., Layton, R.A., Joyce, J., Mazzonetto, M. \& Piwowarczyk, J. (2016) Systems-thinking social marketing: conceptual extensions and empirical investigations, Journal of Marketing Management, 32 (11-12), 1123-1144.

Dorfman, L, \& Krasnow, I. D. (2014). Public health and media advocacy. Annual Review of Public Health, 35, 293- 306.

Elliott-Green, A., Hyseni, L., Lloyd-Williams, F., Bromley, H., \& Capewell, S. (2016). Sugar-sweetened beverages coverage in the British media: an analysis of public health advocacy versus pro-industry messaging. BMJ open, 6(7), e 011295.

Ertekin, Z.O., \& Atik, D. (2015). Sustainable markets: Motivating factors, barriers, and remedies for mobilization of slow fashion. Journal of Macromarketing, 35(1), 53-69.

Ferrell, O.C. \& Krugman, D.M. (1978). The Role of Consumers in the Public Policy Process. Academy of Marketing Science, 6 (3), 167-175.

Finn, A. \& Louviere, J.J. (1992). Determining the Appropriate Response to Evidence of Public Concern: The Case of Food Safety. Journal of Public Policy \& Marketing, 11 (1), 12-25.

French, J. (2013). Business as unusual: the contribution of social marketing to government policymaking and strategy development. In G. Hastings, K. Angus, \& C. Bryant (Eds.), The SAGE Handbook of Social Marketing (pp. 359-374). London: Sage.

French, J. (2014). From the periphery to the core: embedding social marketing in the strategic DNA of all social programmes. In K. Kubacki \& S. Rundel-Theile (Eds.), Contemporary Issues in Social Marketing (pp. 6-20). Cambridge: Scholars Publishers. 
French, J., \& Blair-Stevens, C. (2010). Improving lives together. Westminster City Council, London.

French, J., \& Gordon, R. (2015). Strategic social marketing: SAGE.

Goldberg, M. E. (1995). Social marketing: are we fiddling while Rome burns? Journal of Consumer Psychology, 4(4), 347-370.

Gordon, R. (2012). Re-thinking and re-tooling the social marketing mix. Australasian Marketing Journal (AMJ), 20(2), 122-126.

Gordon, R. (2013). Unlocking the potential of upstream social marketing. European Journal of Marketing, 47(9), 1525-1547.

Gordon, R., Tapp, A., \& Spotswood, F. (2013). From the 4Ps to COM-SM: reconfiguring the social marketing mix. Journal of Social Marketing, 3(3), 206-222.

Gortmaker, Steven L., Boyd A. Swinburn, David Levy, Rob Carter, Patricia L. Mabry, Diane T. Finegood, Terry Huang, Tim Marsh, and Marjory L. Moodie (2011). Changing the Future of Obesity: Science, Policy, and Action. The Lancet, 378 (9793), 838-47.

Hassan, L. M., Walsh, G., Shiu, E. M., Hastings, G., \& Harris, F. (2007). Modeling persuasion in social advertising: A study of responsible thinking in antismoking promotion in eight Eastern EU (European Union) member states. Journal of Advertising, 36(2), 15-31.

Hastak, M., Mazis, M.B. and Morris, L.A. (2001). The Role of Consumer Surveys in Public Policy Decision Making. Journal of Public Policy \& Marketing, 20 (2), 170-185.

Hastings, G. (2007). Social marketing: why should the devil have all the best tunes? : Butterworth-Heinemann.

Hastings, G., Anderson, S., Cooke, E., \& Gordon, R. (2005). Alcohol marketing and young people's drinking: a review of the research. Journal of public health policy, 26(3), 296-311. 
Hastings, G., \& Donovan, R. J. (2002). International initiatives: Introduction and overview. Social Marketing Quarterly, 8(1), 3-5.

Hastings, G., MacFadyen, L., \& Anderson, S. (2000). Whose behavior is it anyway? The broader potential of social marketing. Social Marketing Quarterly, 6(2), 46-58.

Hay, R. (1996). Lessons from the Canadian Anti-Smoking Campaign. In A. Podgórecki, J. Alexander and R. Shields (Eds.). Social Engineering (pp.131-152). Canada: Carleton University Press.

Huang, T.T., Cawley, J.H., Ashe, M., Costa, S.A., Frerichs, L.M., Zwicker, L., Rivera, J.A., Levy, D., Hammond, R.A., Lambert, E.V. and Kumanyika, S.K. (2015). Mobilisation of public support for policy actions to prevent obesity. The Lancet, 385(9985), 24222431.

Hoek, J., \& Jones, S. C. (2011). Regulation, public health and social marketing: a behaviour change trinity. Journal of Social Marketing, 1(1), 32-44.

Hornik, R. (1995). Public health education and communication as policy instrument for bringing about changes in behavior. presented at the meeting of the Society for Consumer Psychology Conference, The role of advertising in social marketing, Atlanta.

Kemper, J. A., \& Ballantine, P. W. (2017). Socio-technical transitions and institutional change: Addressing obesity through macro-social marketing. Journal of Macromarketing, Online First.

Kennedy, A. M. (2016). Macro-social marketing. Journal of Macromarketing, 36(3), 354365.

Kennedy, A. \& Parsons, A. (2012). Macro-social marketing and social engineering: a systems approach. Journal of Social Marketing, 2(1), 37-51. 
Kennedy AM, Kapitan S, Bajaj N, Bakonyi A, \& Sands S, (2017). Uncovering wicked problem's system structure: Seeing the forest for the trees. Journal of Social Marketing. 7 (1), 51-73.

Laczniak, G. R., \& Kennedy, A. M. (2011). Hyper norms: Searching for a global code of conduct. Journal of Macromarketing, 31(3), 245-256.

Kocowski, T. (1976). A System Theory of Human Needs and Sociotechnics. In A. Cherns (Ed). Sociotechnics, (pp.109-122). London: Malaby Press Ltd.

Kojder, A. (1996). Sociotechnics under Authoritarianism. In A. Podgórecki, J. Alexander and R. Shields (Eds.). Social Engineering (pp. 213-224). Canada: Carleton University Press.

Lazarsfeld, P., Berelson, B., \& Gaudet, H. (1948), The People's Choice. New York: Columbia University Press.

Lazarsfeld, P., \& Reitz, J. (1975). An Introduction to Applied Sociology. New York: Elsevier Scientific Publishing Company, Inc.

Lin, N., \& Burt, R. (1975). Differential Effects of Information Channels in the Process of Innovation Diffusion. Social Forces, 54 (1), 256-274.

Lindblom, C.E. (1970). The Policy-Making Process. New Jersey: Prentice Hall.

Lindblom, C. E., \& Woodhouse, E. J. (1980). The policy-making process.

M. Taplin, I. (2014). Who is to blame? A re-examination of fast fashion after the 2013 factory disaster in Bangladesh. Critical perspectives on International Business, 10(1/2), 72-83.

MacNaughton, P., \& Gillan, E. (2011). Re-thinking alcohol licensing. Alcohol Focus Scotland and SHAAP, Edinburgh.

Mannheim, K. (1940). Man and Society. London: Routledge \& Kegan Paul. 
McKeever, B. W. (2013). News framing of autism: Understanding media advocacy and the combating autism act. Science Communication, 35(2), 213-240.

Meier, P. S., Purshouse, R., \& Brennan, A. (2010). Policy options for alcohol price regulation: the importance of modelling population heterogeneity. Addiction, 105(3), 383-393.

Michie, Susan, Maartje M. van Stralen, and Robert West (2011), “The Behaviour Change Wheel: A New Method for Characterising and Designing Behaviour Change Interventions," Implementation Science, 6 (42), 1-11.

Moore, S., Perham, N., \& Shepherd, J. (2006). A Multi-Agency Community Based Intervention to Reduce Excessive Drinking in Cardiff City Centre. Cardiff: Cardiff University.

Narasimhan, C., \& Sen, S. (1983). New Product Models for Test Market Data. Journal of Marketing, 47, 11-24.

Oxfam. (2013). The Bangladesh Accord and why it is important. Retrieved from https://www.oxfam.org.au/2013/12/the-bangladesh-accord-and-why-it-is-important/

Ozanne, J.L., Corus, C. \& Saatcioglu, B. (2009). The Philosophy and Methods of Deliberative Democracy: Implications for Public Policy. Journal of Public Policy \& Marketing, 28 (1), 29-40.

Pappalardo, J.K. \& Ringold, D.J. (2000). Regulating Commercial Speech in a Dynamic Environment: Forty Years of Margarine and Oil Advertising Before the NLEA. Journal of Public Policy \& Marketing, 19 (1), 74-92.

Podgórecki, A. (1990). Sociotechnics: Basic Concepts and Issues. Knowledge in Society, 3 (1), 62-83.

Podgórecki, A., \& Łoś, M. (1979). Multidimensional Sociology. London: Routledge \& Kegan Paul. 
Popper, K. R. (1945). The Open Society and its Enemies (Vol. 1 \& 2). London: Routledge.

Raphael, D. (2003). Barriers to addressing the societal determinants of health: public health units and poverty in Ontario, Canada. Health promotion international, 18(4), 397405.

Rittel, H. W., \& Webber, M. M. (1973). Dilemmas in a general theory of planning. Policy sciences, 4(2), 155-169.

Robertson, T. (1967). The Process of Innovation and the Diffusion of Innovation. Journal of Marketing, 31, 14-19.

Robin, D.P. (1987). The Need for a New Class of Information to Aid Public Policy DecisionMakers. Journal of Public Policy \& Marketing, 6, 58-75.

Rogers, E. (2003). Diffusion of Innovations (5th ed.). New York: Free Press.

Smith, B. (1998). Forget messages... think about structural change first. Social Marketing Quarterly (4), 13-19.

Stead, M., Gordon, R., Angus, K., \& McDermott, L. (2007). A systematic review of social marketing effectiveness. Health education, 107(2), 126-191.

Stromsdorfer, E. W. (1985). Social science analysis and the formulation of public policy: Illustrations of what the president" knows" and how he comes to" know" it. In Social experimentation (pp. 257-282): University of Chicago Press.

Thomas, C., \& Sharp, V. (2013). Understanding the normalisation of recycling behaviour and its implications for other pro-environmental behaviours: a review of social norms and recycling. Resources, Conservation and Recycling, 79, 11-20.

Wallack, L. (2002). Public health, social change, and media advocacy. Social Marketing Quarterly, 8 (2), 25-31.

Wallack, L., Dorfman, L., Jernigan, D., \& Themba, M. (1993). The media connection. Media advocacy and public health: Power for prevention, 53-85. 
Yankelovich, D. (1991). Coming to Public Judgement: Making Democracy Work in a Complex World. Syracuse: Syracuse University Press.

Zetterberg, H. (1962). Social Theory and Social Practice. New York: Bedminster Press. 
Figure 1: The Upstream Decision Making Process

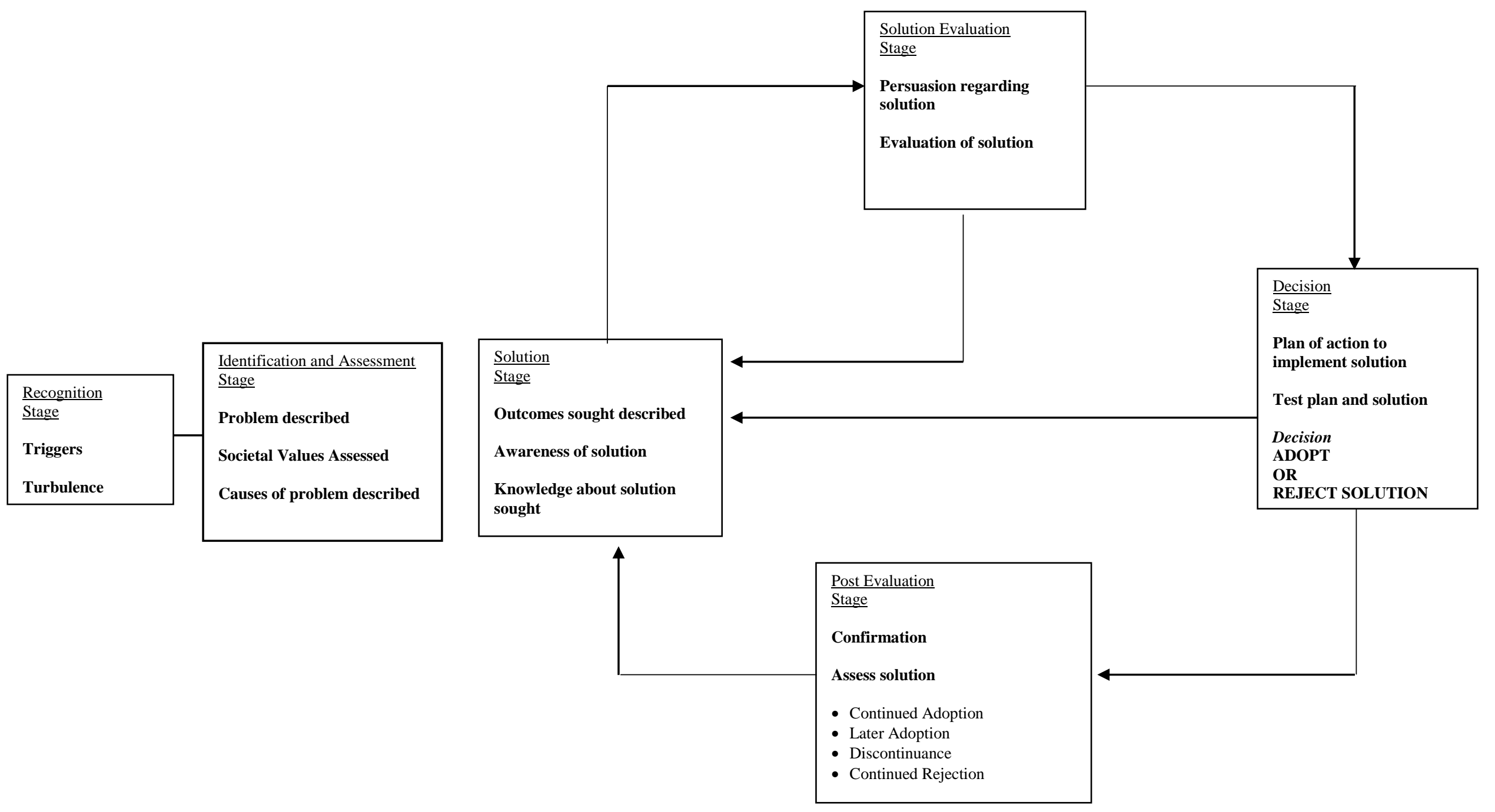

Ann-Marie Kennedy, Joya A. Kemper, Andrew Grant Parsons, (2018) "Upstream social marketing strategy", Journal of Social Marketing, Vol. 8 Issue: 3 , pp.258-279, https://doi.org/10.1108/JSOCM-03-2017-0016 